Article

\title{
Open Geospatial Education
}

\section{Mariana Belgiu *, Josef Strobl and Gudrun Wallentin}

Interfaculty Department of Geoinformatics-Z_GIS, University of Salzburg, Schillerstrasse 30, Salzburg 5020, Austria; E-Mails: josef.strobl@sbg.ac.at (J.S.), gudrun.wallentin@sbg.ac.at (G.W.)

* Author to whom correspondence should be addressed; E-Mail: mariana.belgiu2@sbg.ac.at; Tel.: +43-662-8044-7518; Fax: +43-662-8044-7560.

Academic Editors: Barend Kobben, Serena Coetzee and Wolfgang Kainz

Received: 5 February 2015 / Accepted: 20 April 2015 / Published: 24 April 2015

\begin{abstract}
The advances in open data, free and open source software solutions and open access to research publications have influenced the emergence of open educational resources (OER) initiatives. These initiatives permit access to openly licensed learning resources including courses, webinars, training materials and textbooks. Thereby, an increasing number of users has the opportunity to broaden their knowledge and gain new skills. The goal of this paper is to evaluate open education initiatives in the geospatial domain and its synergies with open spatial data and software movements. The paper is focusing on the Massive Open Online Course (MOOCs) movement. The advantages and challenges of open geospatial education will be thoroughly discussed.
\end{abstract}

Keywords: open education; MOOC; geospatial; GIS; GIScience; GIS\&T

\section{Introduction}

Geospatial technologies and information have become ubiquitous nowadays [1,2]. The geospatial competences required to view and manipulate spatial data and to adequately use geospatial technologies are increasingly sought after by employers [2]. Given the growing importance and recognition of these competences, Geographic Information System and Technologies (GIS\&T) concepts are taught in various education frameworks: (1) Traditional on-campus education offering academic GIS degrees; (2) online distance learning programs leading to academic degrees and certificates [1]; and (3) open, mostly 
non-credit, geospatial education courses aiming at making GIS concepts and technologies accessible and understandable to as many people as possible for free.

The number of open courses designed to introduce GIS\&T concepts to learners with different professional backgrounds, age and educations has increased tremendously over the last years. Despite the open education resources hype, to the best of our knowledge, there is no systematic evaluation of available open geospatial courses. The goal of this paper is to evaluate open education courses in the geospatial domain and their synergies with open spatial data, open web services specifications and open software initiatives. The descriptions and syllabi of open courses designed to introduce GIS concepts and technologies to new learners are analyzed using text mining methods in order to address the following question: What are the common GIS concepts taught in existing open geospatial courses?

The remainder of this paper is set out as follows. Firstly, a brief overview of open education resources and Massive Open Online Course (MOOCs) characteristics are given. This is followed by a detailed discussion of open geospatial courses (called in this paper GeoMOOCs) and synergies between them and cyberinfrastructure, open (geo) data initiatives and free and open source software. In the end, GeoMOOC challenges and sustainability will be discussed.

\section{Online (Open) Education Resources}

Web-based technologies have revolutionized the education process, fostering the development of online courseware and online education programs [3,4]. Today, numerous study programs can be completed at a distance, providing lifelong learning opportunities for those who are looking for professional development [5]. Recently, online education has evolved towards Open Educational Resources (OER). OER imply legally open content licensing under a Creative Commons (CC) license [6] similar to open data, open source software or open scientific publications license terms [7]. Open education is sometimes used interchangeably with the informal learning concept [8]. Unlike formal learning, informal learning activities do not follow the general educational frameworks and constraints imposed by curricula developed for formal learning programs [9]. Among existing open educational resources, Massive Open Online Courses (MOOCs) have become a popular open education model adopted by an increasing number of institutions.

\subsection{Massive Open Online Courses (MOOCs)}

MOOC is an umbrella term referring to online courses that engage a large number of participants [10]. By contrast to traditional online learning courses, MOOCs are open to enrollment by everyone with an Internet connection, with no costs incurred and with no formal education pre-requisites (Table 1). As the learning materials are distributed over the Internet for free, MOOCs can easily scale and accommodate an increasing number of course participants. The openness factor appeals to numerous student types with different enrollment motivation, educational backgrounds, age and countries of origin [11]. In contrast to OER initiatives where learning materials can be downloaded, used and revised by educators and learners, the learning materials available on MOOCs usually are not fully open. The MOOCs openness allows the free access to controlled course materials hosted on easily accessible learning platforms, but without allowing reuse or content repurposing [5]. Annotation features might be an option for further opening, though. 
MOOCs have been divided into two main categories: XMOOCs (exponential MOOCs) and cMOOCs (connectivist MOOCs). The cMOOCs relies on the philosophy of connectivism. Connectivism promotes interaction among learners over social media platforms as the most suitable approach to acquire and extend knowledge and to gain new theoretical and practical skills [10]. The focus of cMOOCs, thus, is on students who interact with each other and even contribute learning resources such as videos or blog posts. XMOOCs encourage massive enrolment and follow a cognitivist-behaviorist approach [10], with an emphasis on individual learning following a pre-determined, instructor-led path through structured learning materials.

Table 1. Differences between traditional classes and MOOCs.

\begin{tabular}{|c|c|c|}
\hline & Traditional (on-Campus) Classes & MOOCS \\
\hline Registration date & Fixed registration period & $\begin{array}{c}\text { Flexible/open registration in case of self-paced } \\
\text { MOOCs; or registration date, class launch date } \\
\text { and completion date in case of scheduled-based } \\
\text { MOOCs }\end{array}$ \\
\hline $\begin{array}{l}\text { Formal } \\
\text { educational } \\
\text { pre-requisites }\end{array}$ & Yes & No \\
\hline $\begin{array}{l}\text { Geographic } \\
\text { coverage }\end{array}$ & Geographically more homogeneous & Wide/global reach \\
\hline $\begin{array}{c}\text { Course } \\
\text { participation }\end{array}$ & Class attendance/synchronous & Online attendance/asynchronous or synchronous \\
\hline Curriculum & $\begin{array}{l}\text { Directed learning: Sequential class } \\
\text { topics starting with introductory } \\
\text { topics, followed by specialized } \\
\text { topics }\end{array}$ & $\begin{array}{l}\text { Non-directed learning: MOOCs dedicated to } \\
\text { introductory topics or a series of courses packed } \\
\text { together lead to specialization certificate }\end{array}$ \\
\hline Scheduling & $\begin{array}{l}\text { Pre-defined course outline and } \\
\text { syllabus }\end{array}$ & Flexible, especially in self-paced MOOCs \\
\hline Evaluation & Final course grade and credit & (Verified) Certificate of completion \\
\hline $\begin{array}{l}\text { Instructor-student } \\
\text { interaction }\end{array}$ & $\begin{array}{c}\text { One-on-one or one-to-many } \\
\text { engagement }\end{array}$ & Group/community engagement \\
\hline $\begin{array}{l}\text { Communication } \\
\text { among enrolled } \\
\text { students }\end{array}$ & Individual learning & Social learning/online learners interaction \\
\hline $\begin{array}{l}\text { Content delivery } \\
\text { Costs }\end{array}$ & $\begin{array}{l}\text { Diverse content delivery mechanism } \\
\text { (Usually) tuition fee }\end{array}$ & $\begin{array}{l}\text { See cMOOCs } v s . \text { xMOOCs } \\
\text { No costs incurred/no penalty for leaving }\end{array}$ \\
\hline
\end{tabular}

MOOCs facilitate participants exploring new topics or strengthening their skills within a professional field without enrolling in formal degree or certificate programs [12]. As demonstrated in a recent study [10], MOOC participants indicate professional development as the primary motivation to take the course. Therefore, these courses shall be geared towards the skills needed to be involved in the workforce [13]. Previous studies have highlighted that MOOC participants are usually young professionals, holding at least an undergraduate degree and wanting to enhance their skills [10,14]. MOOCs therefore offer new educational opportunities by promoting student-centered learning [15] and enabling educational 
institutions to reach new students [4]. A thorough discussion of MOOCs' advantages and challenges is provided here $[10,15]$.

Two course models are promoted by MOOCs: Self-paced or asyncMOOCs (asynchronous MOOCs) and scheduled or syncMOOCs (synchronous MOOCs) [16]. The self-paced model allows participants to start and finish the course whenever they like and to work at their own pace, contrary to the scheduled model. This latter model is less flexible in the sense that the courses following this model have start and end dates, with learning materials accessible only during the scheduled time. Students can work on their selected courses at flexible times of the day and maybe week, but cannot work at their own pace.

The main differences and similarities between MOOCs and traditional formal (offline) classes are summarized in Table 1:

- Registration date: MOOCs are flexible in terms of registration date, except for scheduled MOOCs. The registration flexibility increases the overall diversity of course participants because "as long as enrolments are unrestricted, with no selection mechanism based on commitment or intent, MOOC participants will vary in preparation and goals far more than in traditional residential courses" [17].

- Formal educational pre-requisites: Learners with different backgrounds, trainings and age can participate in MOOCs. The lack of formal educational pre-requisites limiting course access leads to an increasing diversity of learners [18].

- Course participation: MOOCs are not entirely synchronous since the participants attend the course according to their own schedules [10].

- Curriculum: MOOCs do not follow an academic curriculum leading to a degree award. Recently, a series of open courses have been organized into modules that lead to participants' specialization within a specific domain.

- Scheduling: MOOCs are sometimes not strictly operationalized by course outline.

- Evaluation: Students' achievements are assessed through weekly quizzes, periodic assignments and/or final projects. The scalability of the assessment methods need to be adjusted in these global classrooms [5], where the number of participants varies from hundreds to thousands of learners and beyond. Multiple-choice quizzes that can be automatically graded, participation in class discussions (evaluated through the number of discussion threads) [5] and peer assessment tasks are proposed as suitable solutions to assess the achievements of MOOCs participants [10].

- Instructor-student interaction: Given the large number of enrolled MOOC participants, individual instructor-student interaction can be hardly achieved. Therefore, participants are encouraged to interact with their peers and to join online co-learner communities.

- Communication among enrolled students: Online discussion forums, comprising sub-forums for technical feedback, introduction of study groups, readings groups, lecture discussions, final project forums [10,19] or an open Ask me Anything [5] forum section, are important components of MOOCs. Seaton et al. [14] have proven that a large number of enrolled students spend more time on posting or reading discussion threads than on watching featured videos or reading additional learning materials. Analysis of digital traces of online learners reveals that forum participation levels drop significantly towards the end of the course [19]. Therefore, mechanisms for stimulating online forum discussions need to be put into place in order to make online 
communities effectives and sustainable [19]. Some courses require participants to engage in discussions with other course participants and to be active on threaded discussion lists in order to achieve a certificate of completion. This kind of incentive is motivating participants to interact with their peer learners.

- Content delivery: As mentioned above, content development and delivery options vary between xMOOCs and cMOOCs categories.

- Costs: Most current MOOCs are offered for free.

Several education platforms partner with universities and organizations for offering MOOCs: Coursera (www.coursera.org), Udacity (www.udacity.com), edX (www.edx.org), Canvas (www.canvas.net), NovoEd (https://novoed.com/), Open2Study (www.open2study.com), FutureLearn (www.futurelearn.com), iversity (https://iversity.org) or Udemy (www.udemy.com).

Although MOOCs do not grant course credits for obtaining a formal degree, course completion usually is recognized either with free certificates of achievement or verified certificates of achievements. The verified certificate allows users to join a signature track to link the coursework of the users with their identity. The signature track is a means to prevent and hence to eliminate cheating and fraudulent practices [10]. Verified certificates might also be accepted as credit equivalents en lieu of traditional degree courses.

\subsection{GeoMOOCs: What is Special about Open Geospatial Education?}

Several institutions are offering MOOCs in the geospatial domain to attract learners from different background into this field [3,5]. MOOCs designed to introduce GIS or GIS\&T concepts and principles are referred to as GeoMOOCs throughout this paper. The first GeoMOOC, titled "Maps and Geospatial Revolution" was launched in 2013 and attracted tens of thousands of students from around the world [5]. Since then, GeoMOOCs offerings have been constantly growing (see Table 2). These courses take advantage of the increasing availability of open web services hosted on cloud-based platforms, open social media tools such as discussion forums, wikis, open learning materials including tutorials, textbooks, scientific publications and open spatial data and Free and Open Source (FOSS) initiatives [7].

To search and discover existing GeoMOOCs (see Table 2), we used the Class Central (www.class-central.com) and MOOC List (www.mooc-list.com) platforms. The retrieved results were cross-checked with the GeoMOOCs discovered by searching directly in the learning management platforms presented above (e.g., Coursera or Udemy). The following keywords were used to search the mentioned platforms: "GIS", "Geographic Information System", "GIScience”, "spatial”, "geospatial”, "geospatial technologies", "geospatial analysis", "location based service", "GPS", "maps", and "location". To date, twelve GeoMOOCs are registered on the mentioned platforms (Table 2). All evaluated GeoMOOCs resemble the XMOOC category, which means that the courses consist of a series of pre-recorded video lectures and additional reading materials, such as open scientific articles or books. 
Table 2. GeoMOOCs descriptions.

\begin{tabular}{|c|c|c|c|c|c|}
\hline Nr. & Name of the Course & $\begin{array}{c}\text { Learning Management } \\
\text { Platforms/University }\end{array}$ & Certificates & Costs & Course Model \\
\hline 1 & $\begin{array}{l}\text { Maps and the Geospatial } \\
\text { Revolution }\end{array}$ & Coursera/Penn State University & Verified Certificate of completion & free (cost for verified certificate) & Scheduled \\
\hline 2 & $\begin{array}{l}\text { Geospatial Intelligence \& the } \\
\text { Geospatial Revolution }\end{array}$ & Coursera/PennState University & $\begin{array}{l}\text { Verified Certificate of completion or Statement of } \\
\qquad \text { Accomplishment }\end{array}$ & free (verified certificates costs) & Scheduled \\
\hline 3 & $\begin{array}{l}\text { Going Places with Spatial } \\
\text { Analysis }\end{array}$ & Udemy/ESRI & Certificate of completion & free & Scheduled \\
\hline 4 & $\begin{array}{l}\text { From GPS and Google Maps } \\
\text { to Spatial Computing }\end{array}$ & Coursera/University of Minnesota & $\begin{array}{l}\text { Certificate of completion; students completing } \\
\text { more advanced track (called technical track) receive } \\
\text { a distinguished statement of accomplishment }\end{array}$ & free & Scheduled \\
\hline 5 & $\begin{array}{l}\text { Skills for the Digital Earth } \\
\text { (D2L) }\end{array}$ & Desire2learn/Elmhurst College & Certificate of completion * & free & Scheduled \\
\hline 6 & $\begin{array}{l}\text { Geospatial Tech for STEMx } \\
\text { Learning }\end{array}$ & Canvas/Del Mar College & Certificate of completion & free & Self-paced \\
\hline 7 & $\begin{array}{l}\text { Introduction to Geospatial } \\
\text { technology using QGIS }\end{array}$ & $\begin{array}{l}\text { Canvas/Del Mar } \\
\text { Col lege }\end{array}$ & $\begin{array}{l}\text { Opportunity to obtain education credit from a } \\
\text { regionally accredited college }\end{array}$ & free & Scheduled \\
\hline 8 & Mapping with Google & Google & Certificate of completion & free & Self-paced \\
\hline 9 & Basic GIS with gvSIG & gvSIG Association & Certificate of completion & $\begin{array}{l}\text { Free or a small fee for gvSIG user } \\
\text { certification program }\end{array}$ & Self-paced \\
\hline 10 & GIS on the Web & Lynda.com & Certificate of completion & Platform membership fee & Self-paced \\
\hline 11 & Sharpen your GIS Skills & Udemy/Esri experts & Certificate of completion & free & Self-paced \\
\hline
\end{tabular}

*: Advanced modules completion can be used as a waiver for the first courses in the online undergraduate certificate in Geographic Information Systems or Online Master's

Degree or Graduate Certificate in Applied Geospatial Sciences at Elmhurst College. 
The first six GeoMOOCs displayed in Table 2 are designed to introduce basic GIS\&T concepts. The "Maps and the Geospatial Revolution" course [5] focuses on the way in which geospatial technologies impact our lives and introduces the participants the key characteristics of spatial data (data type, projections, scale, etc.), how to create, analyze and visualize spatial data. This course uses Esri's cloud-based ArcGIS Online platform for creating maps and performing spatial analysis. In addition, the open-source CartoDB application is also offered as an option to create online maps. The "Geospatial Intelligence \& the Geospatial Revolution" course explains participants how to use geospatial intelligence (GEOINT) in different domains such as business, defense or law enforcement in order to make informed decisions. The basic GIS\&T concepts such as spatial data type, projections, scale, data sources (remote sensing, drones, open data such as crowdsourced data, proprietary data) and geospatial reasoning are thoroughly discussed in this course. The "Going places with spatial analysis" course offered by Esri focuses on spatial analysis using the tools hosted on the ArcGIS online platform. "From GPS and Google Maps to Spatial Computing" offered by University of Minnesota is organized on three levels: "Curiosity track", "concepts track" and "technical track". The characteristics of spatial data, spatial query language introduced in the first part of the course are followed by spatial networks analysis (connectivity, shortest path), spatial pattern analysis, spatial data sources such as crowdsourcing, Global Positioning System (GPS) and geoparsing technologies and basic cartography concepts (map interpretation, map design projections, scale). "Skills for the Digital Earth (D2L)" introduces fundamental geographic concepts, spatial data features, GIS software (both proprietary and open source), primary and secondary data sources, location-based services and basic elements of cartography. The ArcGIS Online platform is employed in this course to help participants better understand GIS\&T principles. The "Geospatial Tech for STEMx Learning" course establishes spatial literacy and the use of geospatial technologies in different disciplines. Course participants learn how to view, analyze and map spatial data using QuantumGIS (QGIS) open source GIS software and the free indiemapper online mapping platform used to create web maps.

“Introduction to Geospatial technology using $Q G I S$ " introduces geospatial concepts and technologies using QGIS. "Mapping with Google" focuses on introducing Google technologies to course participants, whereas "Basic GIS with gvSIG" is designed to help course participants to get familiar with GIS concepts using the gvSIG open source software. The "GIS on the Web" course is designed to introduce Web GIS concepts and technologies such as Google Maps, Google Earth, Google Fusion Tables, ArcGIS Online, the Esri Application Programming Interface (API) or the Bing Maps platform. "Sharpen your GIS skills" is dedicated to teaching ArcGIS Desktop, ArcGIS and ArcGIS Online capabilities. The evaluated GeoMOOCs are offered in English. Six of the surveyed GeoMOOCs are offered as scheduled courses with defined times for enrollment. ArcGIS Online, Google Maps ArcGIS Desktop and QGIS are the most widely used platforms to practice the skills learned.

To find out the common GIS topics addressed by the evaluated GeoMOOCs, we performed a text analysis of the course descriptions and syllabi. The text analysis was performed using the $\mathrm{R}$ statistical package [20] and its text-mining ("tm") package. Text pre-processing included removal of spelling mistakes and word stemming (e.g., replacing "maps" with "map"). The words "skills", "will”, "course", "module" and "use" were removed from the text corpora as they would have dominated the results. The pre-processed text corpora were analyzed with the help of word clouds and term frequency counts. 
Exploratory analysis with word clouds shows that the evaluated GeoMOOCs have a strong focus on map making, spatial data characteristics, and on introducing GIS technologies s and software (Figure 1). Spatial analysis is also an important topic addressed by GeoMOOCs (Figures 1 and 2). The 'intelligence' term was used in some evaluated GeoMOOCs to emphasize the advantages of adding geospatial intelligence to different application domains such as disaster management or defense. The high frequency of "introduction" and "fundamental" proves that the great majority of the evaluated GeoMOOCs are designed for an introductory level.

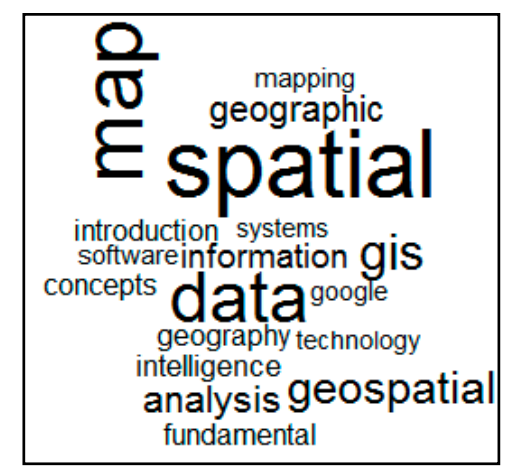

Figure 1. Word cloud of GeoMOOCs syllabi.

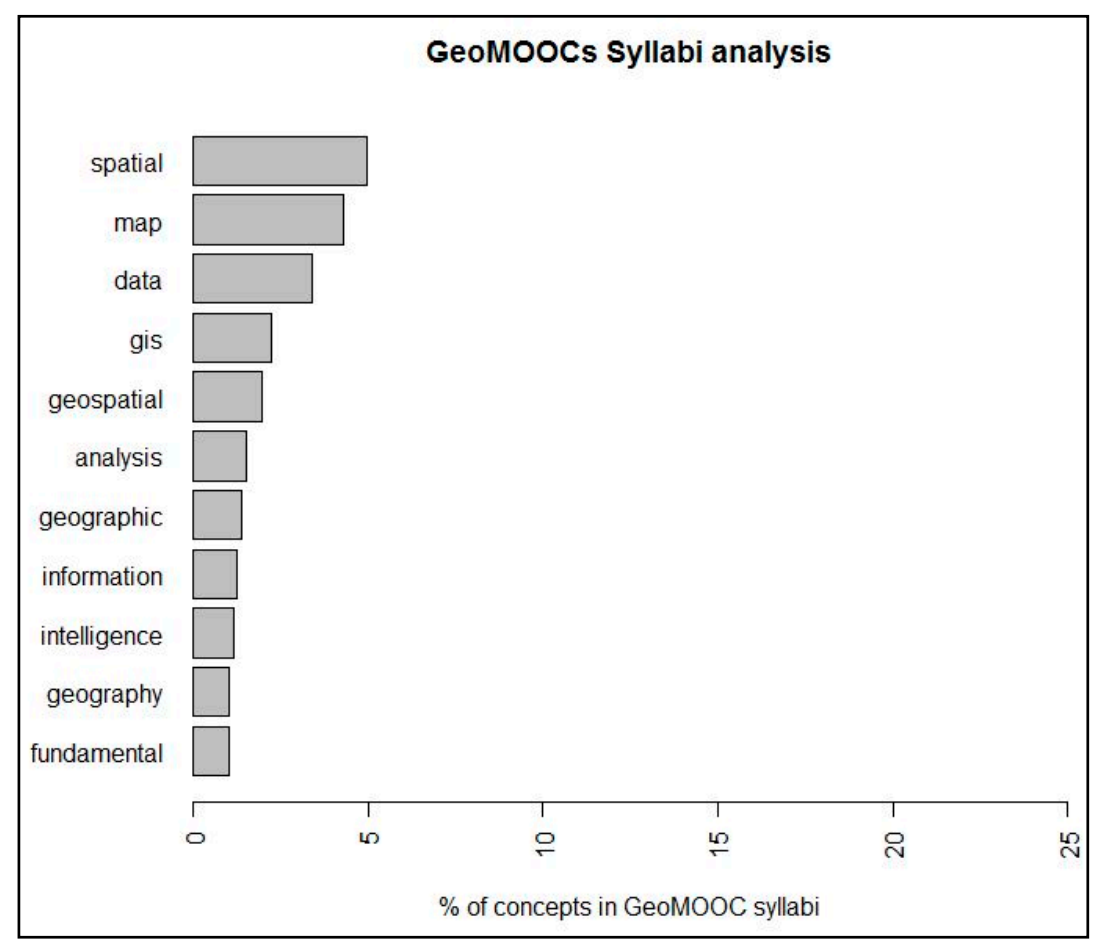

Figure 2. Word frequency counts for key concepts used to describe the available GeoMOOC syllabi.

The common characteristics of existing GeoMOOCs are visualized using word frequency counts (Figure 2). The three top frequency concepts in GeoMOOC syllabi are: "Spatial", "map" and "data". Text analyses also reveal inconsistent use of GIS\&T related terms across the surveyed courses' syllabi. For example, the terms "spatial analysis", "geospatial analysis", and "geographic analysis" are used to refer 
to spatial data manipulation and information extraction. To overcome this terms heterogeneity, the semantics of GIS terms and relations between them need to be explicated into a formal GIS ontology [21].

\section{Synergies between Open Geospatial Education, Cyberinfrastructure, Free and Open Source Software (FOSS) and Open Data}

In the past, the restricted availability of learning resources, software, spatial data and publications have imposed limitations on education [3]. Nowadays, spatial data sharing initiatives and FOSS reduce the prerequisites for improving and democratizing education processes. Three complementary initiatives contribute to spatial data sharing, re-usability and seamless integration across distributed networks: (1) Cyberinfrastructure (CI) and Spatial Data Infrastructures (SDIs); (2) open data sources, such as open government data initiatives and crowdsourced data; and (3) open web services specifications.

CI combines data resources, network protocols, data services, cataloguing services and data analysis services into online platforms that facilitate people to exchange information and collaborate over networks [22]. Geographic CI (GCI) has a focus on geospatial data and information sharing and processing across distributed communities [22]. The realization of CGI was assured by SDI initiatives developed on national, regional and international levels. These initiatives pursue the goal of sharing spatial data in order to avoid geospatial data gap and duplication. The Infrastructure for Spatial Information in the European Community (INSPIRE) Directive defines for example the legal framework for sharing environmental data in the European countries [23]. The INSPIRE Geoportal harvests metadata on existing geospatial data and services, and thus serves as an entry point for searching, discovering and documenting available geographic resources (spatial data and spatial services).

CGI developments lead to the creation of online geoplatforms designed to store, manage and re-use geospatial resources such as geospatial data, geospatial services and applications. These online platforms change the way in which people interact with each other, and with shared information and knowledge items [24,25]. Esri's ArcGIS Online for example is a cloud-based platform, which helps geospatial communities to better access and share spatial data, to conduct spatial analysis without installing any GIS software on desktops or other personal devices, visualize results and share these with a wider community. As this platform is hosted on the cloud, it can easily scale up to accommodate increasing numbers of GeoMOOC participants. Therefore, the scalability feature of cloud GIS platforms together with the increasing amount of geospatial data (reference datasets or thematic data) and geospatial services hosted on the platform creates benefits for GeoMOOC providers, instructors and course participants. MOOC participants can easily create their own maps, access documents created by other course participants and perform advanced spatial analyses such as visibility or crime hot spot analysis without installing GIS software on their personal computers. Seven of the GeoMOOCs listed in Table 2 are using ArcGIS Online to introduce GIS\&T concepts to participants.

CGI data layers benefit from crowdsourced data with continuously increasing geometric and thematic accuracies [26-28] and from open data initiatives [22]. Open Government Data initiatives,such as Data.gov in the United States, Data.gov.uk in the United Kingdom or data.gov.at in Austria (Cooperation Open Government Data Austria), aim at opening up data access (including spatial data) to anyone for free. Teachers can develop individual projects, which encourage students to focus on the understanding of concepts rather than on data acquisition and management [3]. 
Open data and FOSS not only trigger the development of open geospatial resources, but also underpin self-paced learning [18]. Ellul et al. [18] evaluate to what extent FOSS and open data initiatives support self-paced tutorials on spatial databases for students enrolled at the Department of Civil, Environmental and Geomatic Engineering Department of the University College London. This spatial databases curriculum was positively evaluated by more than 25 students. An increasing number of GIS education programs rely on FOSS to teach geospatial concepts and technologies. The PostgreSQL database management system and its spatial extension (PostGIS) together with QGIS and OpenStreetMap (OSM) data are used to teach databases and spatial databases in different GIS educational programs [18]. The advantages of using FOSS in GIS education have been emphasized in [6,18]. QGIS is the most popular GIS software in the evaluated GeoMOOCs (Table 2). Its popularity can be explained by the lively community behind this software and ease of developing new plug-ins using the Python language [29].

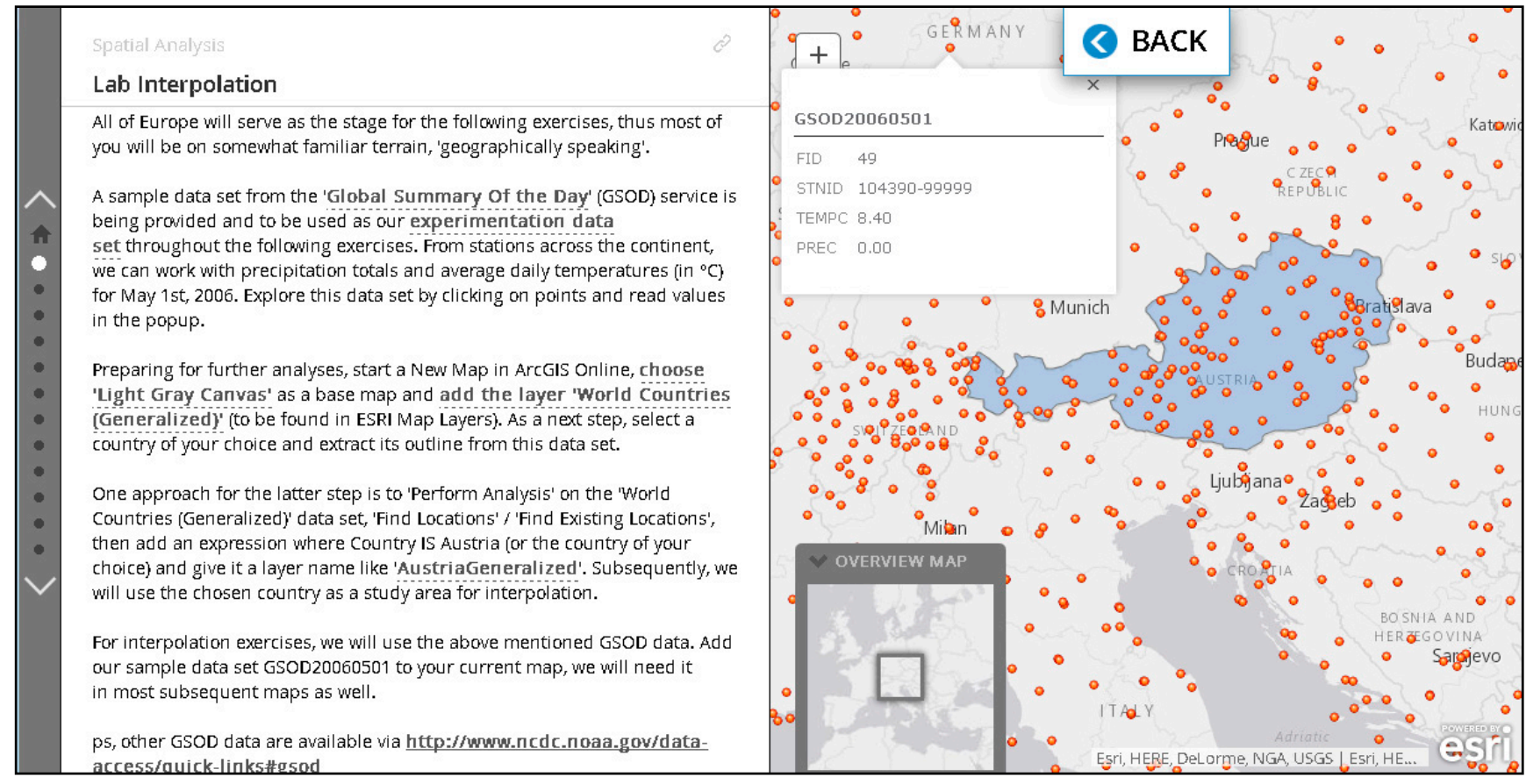

Figure 3. An online application developed to introduce the interpolation concept to the students enrolled in the Applied Geoinformatics MSc, Interfaculty Department of Geoinformatics_-Z_GIS, University of Salzburg, Austria. The learning application can be accessed from the following link: http://goo.gl/uNdCwU.

Spatial data can be easily shared and integrated as open web services into GCI. The Open Geospatial Consortium (OGC) cooperates with various organizations, agencies and academia to pursue the goal of developing open specifications that enable spatial data sharing, integration and processing in a standardized way. Spatial data published using open and interoperable specifications such as Web Feature Service (WFS), Web Map Service (WMS), Web Map Tile Service (WMTS) or Web Coverage Service (WCS) can be easily leveraged and integrated into customized applications through mash-ups [22]. Open services can therefore be accessed in rich online learning apps, designed to encourage student reflection, to motivate and encourage creativity [15]. Online learning apps can be easily reused in different classes. Figure 3 shows an application, developed to introduce spatial interpolation concepts to students enrolled in the Applied Geoinformatics MSc, Interfaculty Department of Geoinformatics-Z_GIS, 
University of Salzburg, Austria. This application was developed using the Map Journal JavaScript API template developed by Esri and hosted on the ArcGIS Online cloud platform.

The advantages of this application can be summarized as follows: (1) hosted on a cloud-based platform, able to scale up to handle an increasing number of students accessing the application simultaneously; (2) leveraging open web services published by different organizations easily mashed-up within the same application; (3) making use of diverse communication media such as text, videos or maps helping to introduce spatial interpolation concepts; and (4) conveniently accessible from desktop or mobile devices as it uses open geoprocessing services hosted and running on the ArcGIS Online platform.

\section{Discussion}

Traditional education programs as well as distance learning programs provide a set of classes based on a coherent curriculum designed to teach GIS principles, concepts and technologies. The successful completion of all classes leads to an academic qualification. Open online geospatial education courses are not (yet) organized into formal educational programs. As already highlighted in Table 2, the completion of a course is documented with a certificate of completion or verified certificate of completion. As a next step, evaluated GeoMOOCs could be organized into series of courses designed to offer GIS specialization certificates. In this context, the student's mastery of the studied learning materials can be evaluated through a capstone project. In addition, learning materials available in GeoMOOCs can be used in traditional and blended formal education programs.

GeoMOOCs are not intended to replace traditional GIS education programs, but rather, to complement and to promote them. Such courses offer learning opportunities for those interested in gaining GIS skills without obtaining an academic degree [10]. Furthermore, GeoMOOCs sometimes are accepted as a waiver for the first courses in a formal degree program (see "Skills for the Digital Earth" GeoMOOC, provided by the Elmhurst College).

The explorative analysis of GeoMOOC syllabi showed that the current GeoMOOCs are focusing on introducing basic GIS concepts, principles and technologies to new learners with an emphasis on generic GIS tasks, such as "data acquisition", "data mapping", and "data analysis" tasks. These key topics align with the knowledge areas and units defined in the GIS\&T Body of Knowledge (BoK) [30]: Geospatial Data, Cartography and Visualization, Analytical methods. The Geospatial Technology Competency Model (GTCM) [31] defines "Positioning and data acquisition" and "Analysis and modeling" as the core industry-sector technical competencies of geospatial professionals. Explorative analysis with word clouds also emphasized that the evaluated GeoMOOCs have a focus on introducing fundamental geospatial competences. The competences such as spatial literacy or spatial thinking are listed as important units in the "Conceptual Foundation" knowledge area defined by BoK [30]. The word frequency analysis revealed that current GeoMOOCs introduce basic "geography" ("and geographic") concepts to course participants. Geography competences are defined in the GTCM as mandatory academic competences to be gained and mastered by geospatial professionals. Some of the competences defined at the bottom of the GTCM pyramid such as academic competences, core geospatial abilities and knowledge are also addressed in the evaluated GeoMOOC. Robinson et al. [5] have also stated that GeoMOOCs are more suitable to introduce basic concepts such as geography or spatial thinking to a novice audience. 
As the number of GeoMOOCs has proliferated in recent years, and we expect that the course designs and topics will diversify, standardized criteria to classify and evaluate the quality of GeoMOOCs have to be developed. Conole [15] proposed several criteria to be considered when evaluating and classifying available MOOCs: degree of openness, scale of participation (number of enrolled learners), multimedia diversity, communication among learners and between learners and instructors, collaboration among course participants, type of learner pathways (learner-centered or teacher-centered), the level of quality assurance, the extent to which reflection is encouraged, the assessment (informal or formal), autonomy and diversity of learning [15]. The feedback provided by the course participants on the quality of the course materials, the "drop-out" rate, the number of discussion threads [5], or the software (and software diversity) used throughout the course could be added to the above-mentioned criteria.

We expect future education materials to take advantage of: (1) Cloud computing platforms capable of offering a wide variety of open web services to an increasing number of users; (2) data sharing through CGI, SDI and open data initiatives; (3) open software solutions; (4) open services specifications; and (5) open learning materials including open access scientific publications.

\section{Conclusions}

This paper discussed the key characteristics of MOOCs with a special focus on open education courses designed to introduce GIS\&T concepts to new learners (GeoMOOCs). The synergies of GeoMOOCs with Cyberinfrastructure, open data, open specifications and FOSS movements are emphasized. Most of the evaluated GeoMOOCs use the ArcGIS Online cloud platform to introduce the GIS concepts and technologies. Thus, these courses reap the benefits of cloud-based applications scaling up to handle potentially massive numbers of participants simultaneously accessing course materials, assignments, spatial data and maps. The QGIS software proves to be the most popular open source GIS software used in the evaluated GeoMOOCs. The main topics introduced by current GeoMOOCs are compared with the knowledge areas defined by BoK [30] and the geospatial competences specified in the GTCM [31]. Most of the evaluated GeoMOOCs are designed to introduce fundamental GIS\&T concepts. Geospatial data, cartography and visualization and analytical methods are the key BoK knowledge areas covered by the current open geospatial courses. GeoMOOCs dedicated to software and application development and web technologies are expected to be developed in the future.

In future research, the following open questions should be addressed: Who are the target groups of GeoMOOCs? Are GeoMOOCs the proper venue to open up geospatial education or is it primarily a "marketing strategy" [15] for promoting specific GIS software solutions or existing educational programs?

\section{Author Contributions}

All three authors have an equal contribution.

\section{Conflicts of Interest}

The authors declare no conflict of interest. 


\section{References}

1. Goodchild, M.F. The Fourth R? Rethinking GIS Education. Avialable online: http://www.esri.com/ news/arcnews/fall06articles/the-fourth-r.html (accessed on 30 January 2015).

2. Riihelä, J.; Mäki, S. Designing and implementing an online GIS tool for schools: The Finnish case of the PaikkaOppi Project. J. Geogr. 2014, 114, 15-25.

3. Strobl, J. Time to Open Up. Available online: http://geospatialworld.net/uploads/magazine/ January-2015-Geospatial-World-Magazine/index.html (accessed on 22 April 2015).

4. Dong, S.; Xu, S.; Lu, X. Development of online instructional resources for Earth system science education: An example of current practice from China. Comput. Geosci. 2009, 35, 1271-1279.

5. Robinson, A.C.; Kerski, J.; Long, E.C.; Luo, H.; DiBiase, D.; Lee, A. Maps and the geospatial revolution: Teaching a massive open online course (MOOC) in geography. J. Geogr. High. Educ. $\mathbf{2 0 1 5}, 39,65-82$.

6. OECD Giving Knowledge for Free: The Emergence of Open Educational Resources. Available online: http://www.oecd.org/edu/ceri/38654317.pdf (accessed on 1 April 2015).

7. Sui, D. Opportunities and impediments for open GIS. Trans. GIS 2014, 18, 1-24.

8. McAndrew, P. Defining openness: Updating the concept of "open" for a connected world. J. Interact. Media Educ. 2010, doi:http://dx.doi.org/10.5334/2010-10.

9. Livingstone, D.W. Adults' Informal Learning: Definitions, Findings, Gaps and Future Research; Centre for the Study of Education and Work, OISE/UT: Toronto, ON, Canada, 2001.

10. Hew, K.F.; Cheung, W.S. Students' and instructors' use of massive open online courses (MOOCs): Motivations and challenges. Educ. Res. Rev. 2014, 12, 45-58.

11. DeBoer, J.; Ho, A.; Stump, G.S.; Pritchard, D.E.; Seaton, D.; Breslow, L. Bringing student backgrounds online: MOOC user demographics, site usage, and online learning. In Proceedings of the 6th International Conference on Educational Data Mining, Memphis, TN, USA, 6-9 July 2013.

12. ArcNews ESRI to Offer Spatial Analysis MOOC. Available online: http://www.esri.com/esri-news/ arcnews/summer14articles/esri-to-offer-spatial-analysis-mooc (accessed on 24 January 2015).

13. Hofer, B.; Wallentin, G.; Traun, C.; Strobl, J. Workforce demand assessment to shape future GI-Education-First results of a survey. In Proceedings of the 17th AGILE Conference on Geographic Information Science, Castellón, Spain, 3-6 June 2014.

14. Seaton, D.; Chuang, I.; Mitros, P.; Pritchard, D. Who does what in a massive open online course? Educ. XPress 2013, 2013, 1-1.

15. Conole, G. MOOCs as disruptive technologies: Strategies for enhancing the learner experience and quality of MOOCs. Rev. Educación Distancia 2013, 39, 1-17.

16. Clark, D. MOOCs: Taxonomy of 8 types of MOOC. Donald Clark Plan B Blog. Publ. 2013, $16,4-13$.

17. DeBoer, J.; Ho, A.D.; Stump, G.S.; Breslow, L. Changing “course” reconceptualizing educational variables for massive open online courses. Educ. Res. 2014, doi:10.3102/0013189X14523038.

18. Ellul, C. Can free (and open source) software and data be used to underpin a self-paced tutorial on spatial databases? Trans. GIS 2012, 16, 435-454.

19. Gillani, N.; Eynon, R. Communication patterns in massively open online courses. Internet High. Educ. 2014, 23, 18-26. 
20. R-Development-Core-Team. R: A Language and Environment for Statistical Computing; R Foundation for Statistical Computing: Vienna, Austria, 2013.

21. Li, N.; Raskin, R.; Goodchild, M.; Janowicz, K. An ontology-driven framework and web portal for spatial decision support. Trans. GIS 2012, 16, 313-329.

22. Yang, C.; Raskin, R.; Goodchild, M.; Gahegan, M. Geospatial cyberinfrastructure: Past, present and future. Comput. Environ. Urban Syst. 2010, 34, 264-277.

23. Craglia, M.; Annoni, A. INSPIRE: An innovative approach to the development of spatial data infrastructures in Europe. In Research and Theory in Advancing Spatial Data Infrastructure Concepts; Onsrud, H., Ed.; ESRI Press: Redlands, CA, USA, 2007; pp. 93-105.

24. Yang, C.; Xu, Y.; Nebert, D. Redefining the possibility of digital Earth and geosciences with spatial cloud computing. Int. J. Digit. Earth 2013, 6, 297-312.

25. Hofer, B. Uses of online geoprocessing technology in analyses and case studies: A systematic analysis of literature. Int. J. Digit. Earth 2014, doi:10.1080/17538947.2014.962632.

26. Goodchild, M.F.; Li, L. Assuring the quality of volunteered geographic information. Spat. Stat. 2012, 1, 110-120.

27. Haklay, M. How good is volunteered geographical information? A comparative study of OpenStreetMap and Ordnance Survey datasets. Environ. Plan. B Plan. Des. 2010, 37, 682-703.

28. Heipke, C. Crowdsourcing geospatial data. ISPRS J. Photogramm. Remote Sens. 2010, 65, 550-557.

29. Teodoro, A.C.; Duarte, L. Forest fire risk maps: A GIS open source application-A case study in Norwest of Portugal. Int. J. Geogr. Inf. Sci. 2012, 27, 699-720.

30. DiBiase, D.; DeMers, M.; Johnson, A.; Kemp, K.; Luck, A.T.; Plewe, B.; Wentz, E. Introducing the first edition of geographic information science and technology body of knowledge. Cartogr. Geogr. Inf. Sci. 2007, 34, 113-120.

31. DiBiase, D.; Corbin, T.; Fox, T.; Francica, J.; Green, K.; Jackson, J.; Jeffress, G.; Jones, B.; Jones, B.; Mennis, J. The new geospatial technology competency model: Bringing workforce needs into focus. URISA J. 2010, 22, 55-72.

(C) 2015 by the authors; licensee MDPI, Basel, Switzerland. This article is an open access article distributed under the terms and conditions of the Creative Commons Attribution license (http://creativecommons.org/licenses/by/4.0/). 